\title{
ETRI Journal 20년을 회고하며
}

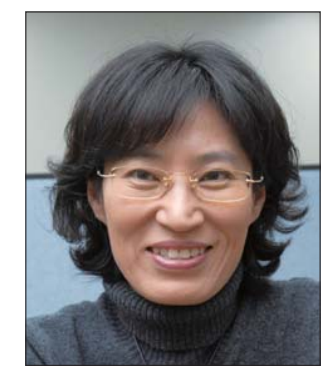

글 김명순

EIRI저널 Managing Editor 한국전자통신연구원 연구협력팀

\section{ETRI와 ETRI Journal의 탄생}

1960년대 이후 한국의 통신시장은 경제성장과 맞물 려 수요가 급증하였으나 통신 공급이 수요를 따라가지 못하였기 때문에 전화적체 현상이 날로 심각해졌다. 정 부는 이러한 전화적체를 해소하기 위해 전자식 교환기 의 도입 및 기술개발을 총괄할 전문연구기관의 설립이 필요하다는 판단 아래 1976년 12월 한국과학기술연구 소 부설 한국전자통신연구소를 설치하게 되었다. 이는 이듬해 1977년 12월 '특정연구기관 육성법 시행령' 개 정에 의해 체신부 산하 한국통신기술연구소(KTRI)로 정식 출범하게 되었다.

한편, 전자산업은 1960 년대 후반 이후 경제성장을 주도하는 산업으로 주목받으며 정부의 적극적인 지원 과 외국기업의 유치, 그리고 국내기업들의 노력 등에 힘입어 더욱 급속도로 성장했다. 그러나 1973년 석유 파동을 겪으며 경제성장의 견인차 역할을 하던 전자산 업이 위기를 맞게 되자 정부는 이를 계기로 전자산업을
노동집약형에서 기술집약형으로 전환하기 위한 독자적 인 연구개발체제를 확립할 필요성을 절감하게 되었다. 이에 따라 1976년 당시 구미 전자산업전문단지에 소재 한 한국전자기술연구소(KIET)를 상공부 산하의 연구 기관으로 공식 출범시키게 되었다.

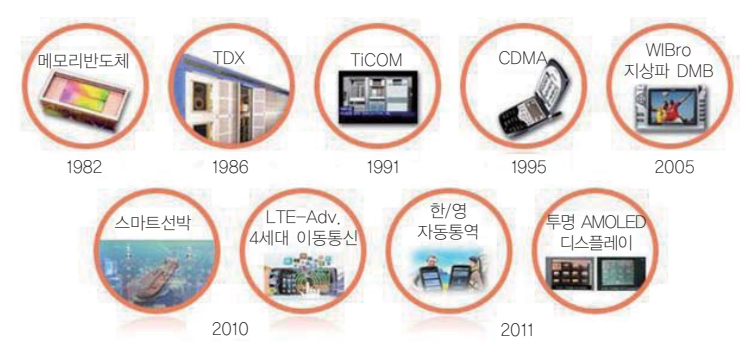

〈그림 1〉 ETRI의 주요 연구 성과

이후 통신 및 전자 분야의 기술개발 노력은 1980 년 대 초반까지 꾸준히 이어져 1982년 초 TDX-1X의 개 발 및 시험 운용을 시작하게 되었다. 거듭된 연구개발 의 노하우가 축적되어 연구진들은 점차 자신감을 가지 
게 되었으나, 선진국에 비하면 기술수준은 여전히 미흡 한 상태였다. 1980년대 중반부터 주요 선진국들은 하 드웨어 중심의 산업구조를 첨단기기와 소프트웨어 산 업 중심으로 급격하게 전환시키는 추세에 있었다. 특히 반도체와 컴퓨터, 통신기술의 결합으로 음성, 데이터, 화상 등 다양한 정보를 동시에 송출하는 종합적인 정보 통신을 구현하기에 바빴다. 우리나라도 선진국 수준의 기술을 확보하기 위해서는 각 부문별로 균형 있는 기술 개발과 함께 이들 간의 상호 교류와 결합이 용이한 연 구개발 체제의 구축이 필요하다는 정부의 판단에 따라, 두 연구소는 1985년 3월 통합되어 전자· 통신 기술을 아우르게 되면서 한국전자통신연구소(ETRI)라는 이름 의 국책연구소로 거듭나게 되었다. 이후 ETRI는 1980 년대, 1990년대, 2000년대를 거치면서 부단한 연구개 발을 수행하였고 그동안의 주요 성과는 다음의 그림처 럼 집약될 수 있다.

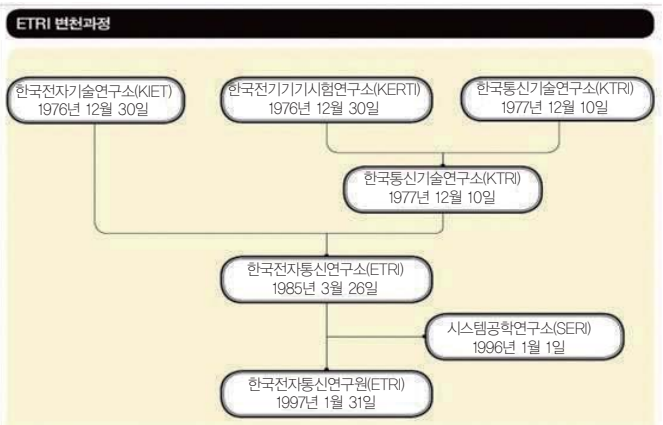

〈그림 2〉 ETRI의 변천 과정

한편, 1993년, 당시 수장이었던 양승택 원장은 ETRI 가 명실상부한 세계적 수준의 연구기관으로 발전하기 위 해 ETRI의 독창적인 연구결과를 국내 및 세계에 널리 알 릴 필요가 있다는 비전을 밝히고 당시 기관지였던 『전자 통신」을 ETRI Journal로 바꾸고 영문 기관지로 새롭게 출발하였다. 그리고 기관지 고유의 성격에 맞게 ETRI에
재직하는 연구원이 생산한 논문만을 투고받았다.

ETRI Journal은 ETRI 연구원들의 연구과제 수행과 정에서 창출된 독창적인 연구결과를 세계에 알리겠다 는 목표 외에 이 학술지를 관련 분야에서 세계적인 지 명도를 자랑하는 질 높은 저널로 육성하겠다는 뚜렷한 목표의식 아래 세계적인 전문가 5 명의 엄격한 심사를 거쳐 질 높은 논문만 게재한다는 원칙을 고수해왔다.

1996년 1월 ETRI Journal은 당시 주요 저널 색인 데이터베이스인 과학기술논문 인용색인(SCI Expanded), INSPEC, Current Contents, Research Alert 등에 등재됨으로써 전 세계에 알려지기 시작하 였고, 1998년 4월부터는 SCI 목록에 등재되어 IT 분야 역사상 명실상부한 국내 최초의 SCI저널로 자리 매김하 게 되었다. 당시 ETRI Journal의 SCI 등재는 국내 저 널로서는 네 번째였으며, 전 세계 정보통신 분야에서 학 회지 등이 아닌 기관지로서도 네 번째로 이룬 쾌거였다.

당초 ETRI Journal은 ETRI의 독창적이고 우수한 연구결과를 전 세계에 알릴 목적으로 시작된 저널이었 지만, 2001년부터는 레터논문도 게재하게 되었다. 일 반적으로 저널 논문들이 투고에서 게재될 때까지 약 1 2년 정도 소요되는 점을 보완하기 위해 논문의 신규 성 · 파급효과·시의성 등이 높은 3 4쪽 분량의 짧은 논문을 신속히 게재함으로써 지식의 확산에 기여하고 자 하기 위해서였다. 또한 투고 및 개재논문이 증가함 에 따라 정보전달의 속도를 높이기 위해 2002년부터는 격월간으로 발행하기 시작하였다.

1) 현재 ETRI Journal 심사시스템 데이터베이스에는 그동안 ETRI Journal논문의 심사를 담당한 국제심사자 5,500여 명의 정보가 누적되어 있다. 


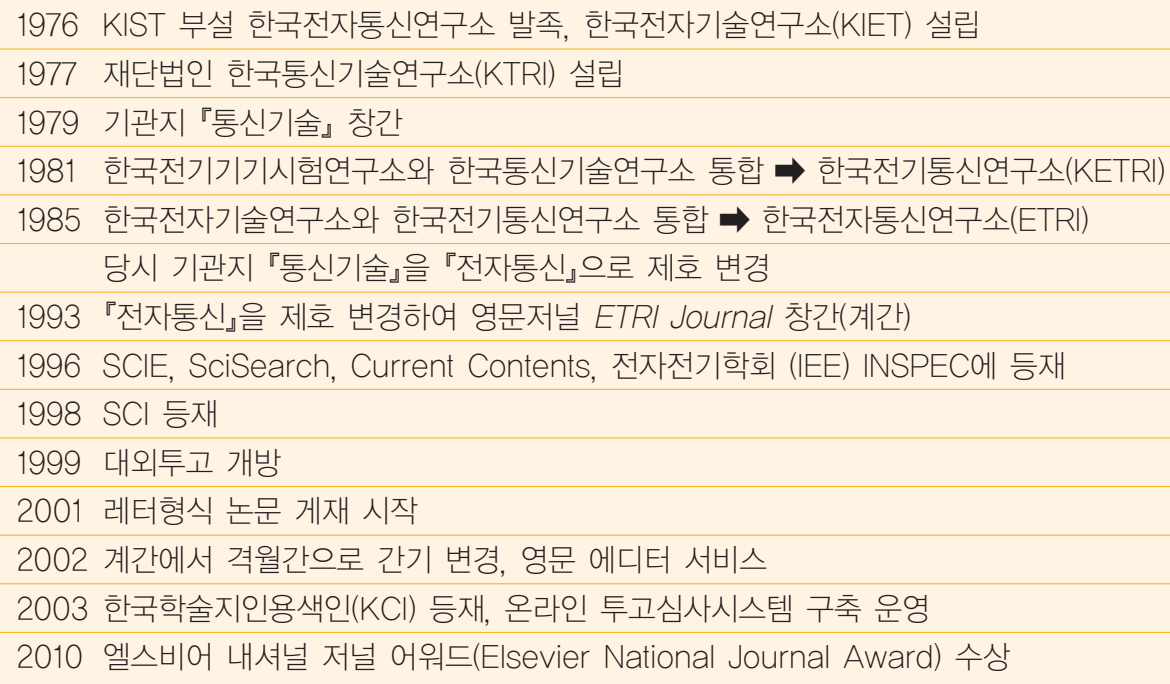

\section{〈그림 3〉 ETRI와 ETRI Journal의 역사}

\section{ETRI Journal이 SCI에 등재되기까지}

이제 ETRI Journal이 SCI에 등재되는 과정을 자세 히 살펴보도록 하자. ETRI Journal이 SCI 등재 준비 를 염두에 두게 된 것은 영문저널 창간 이후 2 년째인 1994 1995년 무렵이었다. 편집위원회에서 "ETRI Journal이 어떻게 SCI 저널로 발돋움 할 수 있겠는가" 라는 화두에 대해 거듭 논의하였고, 당시 편집위원장이 었던 이일항 박사께서 보다 심층적인 탐색을 위해 1995년 9월 미국 ISI사를 방문하기에 이르렀다. 물론 그 이전 약 1 년 동안 ISI 측과 이메일 등 서신 교환을 통해 ETRI Journal의 취지, 성격, 내용, 재정적인 후 원, 목표 등에 대한 설명 자료를 주고받았음에도 직접 방문하게 된 것은 면담을 통해 ISI 측의 평가기준을 보 다 면밀히 파악하기 위해서였다. 그리고 ETRI Journal 의 성격이 당시 AT\&T의 Bell Labs Technical Journal과 유사하다는 것, 홍보저널이 아니라 학술저 널이라는 것, 세계적인 논문심사 기준과 체계를 가지고
있다는 것, 학술지 정보의 세계적인 유통이 목적이라는 점 등을 주로 알리기 위해서였다.

ISI사에서 저널을 선별하고 평가하는 기준으로는, 논 문의 학술성은 말할 것도 없고, 저자와 편집위원에 대 한 국제적인 명성 및 학술적 지위를 고려하는 것은 물 론 게재논문의 인용도에 대해서도 결정적인 사안으로 취급하였다. ETRI Journal은 당시 창간한 지 2 년밖에 되지 않은 저널이라 ISI사의 데이터베이스에 올라 있는 평가자료는 거의 전무한 상태였다. 그럼에도 방문하게 된 것은 일단 적극적인 홍보 노력은 다소 좋은 인상을 심어줄 수 있을 것이라는 희망 때문이었다고 한다.

편집위원장이 ISI 담당자로부터 얻은 조언의 골자는 평가착수부터 SCI 등록까지 일반적으로 최소한 5년은 걸린다는 점, 그리고 무엇보다도 인용도가 높아야 한다 는 것이 주된 내용이었다. 특히 편집위원장과 편집위원 에 대한 평가는 1 차적인 것으로서 매우 필수적인 사항 이라고 하였다. 더불어 ETRI Journal의 엄격한 논문 심사과정으로 보아 논문의 질적 수준은 매우 높은 것으 
로 판단되니 1996년 1월 1일부터 SciSearch, Current Contents에 인덱싱하여 세계적으로 인용될 수 있도록 도와주겠다는 약속을 받았다. 이에 편집위원장은 기쁜 마음에 이듬해 다시 방문하겠다는 의사를 표시하였으 나, 담당자는 더 이상 방문할 필요가 없다고 하면서 인 용도가 제 궤도에 오르는 데 몇 년은 걸릴 것이고 언제 든지 합격하면 통보가 갈 것이니 계속 질 좋은 논문만 내놓으라고 답변하였다.

1996년 4월에는 전자전기학회(IEE, Institute of Electrical Engineering)에서 인스펙(INSPEC)에 등록 한다는 기쁜 소식을 듣게 되었다. 이후 편집위원장은 지 속적인 이메일 작업 등을 통해 ISI 측에 ETRI Journal 을 상기시키려 노력하였고, 1996년 9월에는 다시 ISI를 방문하였다. 그러나 1995년도 인용지수가 0.1에도 미치 지 못했으므로 아쉽지만 발걸음을 돌려야 했다.

그런데 해를 넘기면서 상황은 달라졌다. 1996년 말 다이얼로그(Dialog) 데이터베이스를 검색하였을 때, 1994년과 1995년 논문의 1996년도 인용지수는 0.6을 상회하고 있었다. 이는 당시 통신 분야와 전자정보 분 야에서 상위 삼분의 일의 수준에 들어가는 성적이었다. 따라서 1997년 초부터는 혹시나 하는 기대감을 가지게 되었고 1997년 5월 28일 드디어, ETRI Journal이 1998년 4월부터는 SCI 목록에 실릴 것이라는 좋은 소 식을 받게 되었다. 창간 후 불과 3 년 만에 이루어진 일 이었다. 이처럼 빠른 시간에 SCI 등재가 결정된 저널은 많지 않을 것이다. 그야말로 요즘 유행어로 표현하자면 '코리언 스타일(Korean style)' 이 아닐 수 없다.

물론 어려움도 많았다. 한때는 투고논문이 부족하였 는데 심지어 저널 발간을 일시적으로 1 2회 중단하는 것에 대해 심각하게 고려한 적도 있었다고 한다. 사실 아무리 ETRI 연구원이라 해도 자신의 우수한 연구 성과 를 세계적으로 명성이 높은 저널에 싣고자 하지, 아직
알려지지 않은 신생 저널에 투고하기 쉽지 않았을 것이 다. 용기가 필요한 모험이었을 것이다. 연구자 개인으로 서의 위험과 불이익을 무릅쓰고 오로지 'ETRI Journal 을 세계적 저널로 만들자'는 일념으로 열심히 집필하여 ETRI Journal에 투고해준 ETRI의 연구자들이야말로 오늘의 ETRI Journal이 있게 한 진정한 공로자들이다. 1997년, 한국 사회가 IMF 구제금융 위기를 겪을 때 ETRI Journal은 또 한 번의 위기를 겪게 되었다. 많은 연구자들이 ETRI를 떠나 대학교수, 벤처기업 등으로 자리를 옮겼고 그런 와중에 연구결과의 산출도 자연히 미진할 수밖에 없었다. 한편 자기 논문을 우수한 저널 에 출판하고자 하는 국내 대학 및 학계의 열기가 매년 고조되고 있었으나 이들이 국제수준의 SCI 저널에 문 을 두드리는 것이 쉽지는 않았다. 이에 따라 1999년부 터는 ETRI 내에서의 역할뿐만 아니라 이러한 국가적 인 차원에서의 역할 및 기대치를 반영하여 투고 자격을 국내외 관련 연구자에게 전면 개방하였다. 이후 2012 년 현재까지 일체의 투고비용 및 게재료를 받지 않고 오로지 우수한 내용의 논문이면 전 세계 어디서나 누구 든 자유롭게 투고하고 게재할 수 있도록 한다는 원칙을 유지하고 있다.

1990년대 당시, 우리나라 과학 학술지의 국제적인 입지는 열악하였고 특히 정보통신 분야에서의 SCI 저 널이 전무한 상태였기에, ETRI Journal의 SCI 등재는 ETRI의 차원을 넘는 것이었다. 나아가 우리나라 전 자·정보통신 국책연구의 중심체가 세계적인 수준의 우수학술지를 가지게 되었다는 점은 국내 학계 및 연구 자를 고무시키는 매우 의미 있는 일이었다. 


\section{ETRI Journal의 발자취 20년}

『ETRI 저널』의 과거 20년간의 발자취를 한눈에 살 펴볼 수 있도록 몇 가지 그림으로 표현해보았다.

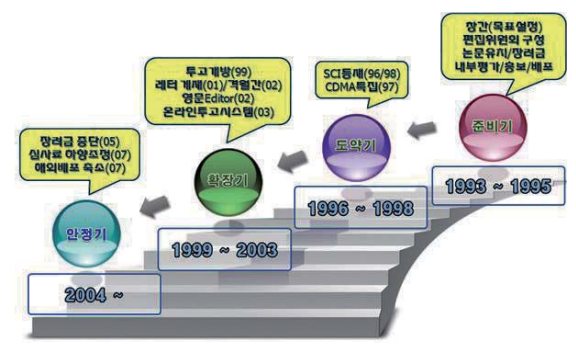

그림 4. `ETRI 저널」의 발자취

1993년 창간 때부터 1996년까지 약 3년간은 저널 창 간에 따른 기초적인 인프라를 구축하고 편집위원회 시 스템을 갖추는 시기였다. 이후 SCI 등재를 계기로 세계 무대로 발돋움하는 과정을 거쳐 1990년대 후반과 2000 년대 초 사이는 투고의 문호를 국내외로 개방하 고 확장해 나가는 시기였다고 할 수 있다.

이 기간 동안 ETRI는 ETRI Journal을 우수한 기관 지로 육성하기 위해 인적 - 물적 지원에 아낌없이 투자 하였다. 논문 게재 시 저자에게 게재료를 받는 것이 아 니라 오히려 게재장려금을 지급하였고, 편집위원의 활 동비 지급은 물론 당시 지명도가 없었음에도 불구하고 투고논문을 심사해준 국제심사자에게 감사의 뜻으로 보상 챙기기를 게을리하지 않았다.

또한 이 기간에는 무엇보다도 ETRI Journal의 존재 를 외부에 알리는 데 주력하였다. 1996년부터 미국의 커런트 콘텐츠, 사이서치, 리서치 앨러트, 엔지니어링 인덱스(Engineering Index) 등에 등록되면서 서서히 국제적으로 알려지기 시작했고, 더불어 당시 ETRI 기 술정보센터에서 개발하여 제공하던 데이터베이스인 ETLARS를 통해 온라인상에서의 전문(full text) 서비
스를 시작하였다. 인쇄본 책자에도 당시로서는 상당한 인쇄비를 투자하여 우리보다 기술 수준이 앞선 선진국 의 주요 대학 중앙도서관 및 전기전자 - 정보통신 관련 학과, 세계 유수의 정보통신 관련 연구소, 기업, 국내외 각종 도서관 등에 거의 무차별적으로 배포하다시피 하 여 홍보에 전력 질주하였다.

학술지 이미지를 대표하는 표지 디자인은 창간 당시 유사 학회지들의 디자인을 참고하여 네모 박스 안에 각 호의 대표 논문 또는 우수 논문의 그림을 삽입하는 방 식을 사용하기 시작했다. 이는 해를 거듭할수록 일종의 전통이 되어왔다. 그러나 최근 여타 학술지가 보여주는 세련된 느낌의 밝은 색상 등 새로운 면모의 표지 디자 인과 비교할 때 ETRI Journal의 표지는 다소 오래된 듯한 느낌을 줄 수 있겠으나 이 또한 전통의 맥을 이어 간다는 차원에서 오히려 신선할 수 있으므로 초창기의 표지 디자인을 계속 유지하고 있다. 이렇듯 변하지 않 는 이미지를 통해 독자와의 신뢰를 쌓고, 언제 어디서 든 도서관의 서가 등에서도 한눈에 ETRI Journal임을 알아볼 수 있도록 일관된 이미지를 구축하고자 하였다.

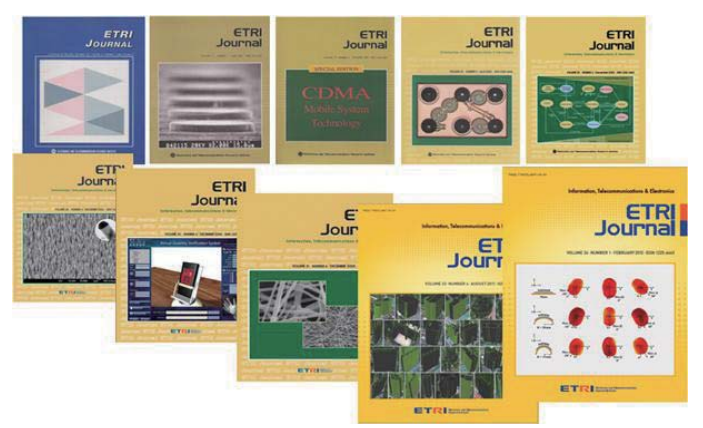

그림 5. "ETRI 저널`의 표지 디자인들

2002년부터는 게재논문 영문의 질적 향상을 위해 영 문교정을 전담하는 영어권 출신의 에디터(english language editor)를 고용하여 영문 감수 서비스를 제 
공하는 등 편집위원의 국제화는 물론이고 가용한 여러 채널을 통해 학술지의 질적 향상을 위한 투자를 아끼지 않고 있다.

이러한 20 여 년에 걸친 노력의 결과, 이제 ETRI Journal은 게재 장려금, 심사료 등의 직접적인 촉진책 이나 지원책이 없이도 운영에 지장이 없는 안정기에 접 어들었다고 할 수 있다. 2010년에는 세계 최대의 출판 사인 엘스비어(Elsevier)가 선정하는 내셔널 저널 어워 드(National Journal Award)를 수상함으로써 명실상 부하게 대한민국을 대표하는 학술저널임을 객관적으로 입증받게 되었다.

한편, 논문 분포를 살펴보면 아래 그림에서 보듯이 투고논문이 1999년 투고 개방 이후 해마다 급격히 증 가하고 있음을 알 수 있다. 『ETRI 저널』홈페이지 (http://etrij.etri.re.kr)를 통한 전문(full text) 제공 서비스는 물론이고 저널이 발간될 때마다 전 세계 관련 연구자 약 1 만 7 천 명에게 웹진 형태의 이메일 서비스 를 제공하는 한편 (구독료, 투고료, 심사료, 게재료 등 이 없는) 100 퍼센트 무료 저널로서 세계 어디서나 논문 을 무료로 받아보고 투고할 수 있는 프리 액세스 저널 (Free Access Journal)로 운영하고 있다. 이에 힘입어 해외 투고논문도 꾸준히 증가하고 있는데 2011년 말 기준으로 할 때 해외 50 여 개 국가에서 총 744 건이 투 고되어 이는 전체 투고논문 1천165건 중 64퍼센트에 달하는 비중이다. 한편, 논문 게재율은 해마다 낮아져 1990년대에는 평균 60퍼센트, 2000년대에는 26퍼센 트의 게재율을 보였으나 2010년대에 들어서는 약 10퍼 센트 정도로 낮아졌다.

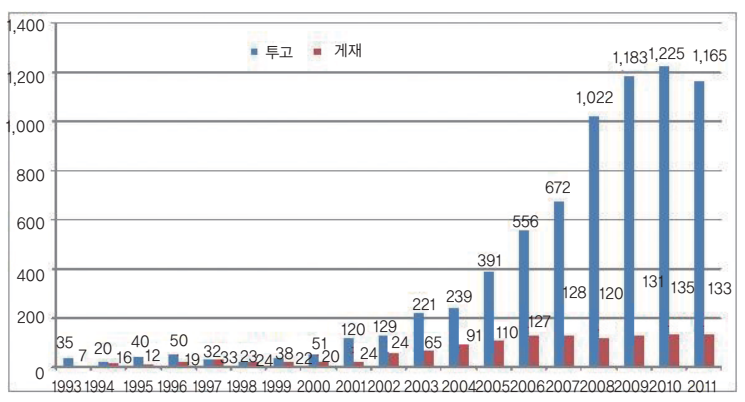

그림 6. ${ }^{\circledR} E T R I$ 저널」의 투고논문 게재율

\section{ETRI Journal에게 주어진 과제}

그렇다면, ETRI Journal에 남은 숙제는 무엇일까? 사실 단기간 ETRI Journal이 SCI의 주요 저널(core journal)로 성장할 수 있었던 것은, 일차적으로 ETRI 내부에 전기전자 - 정보통신 분야와 관련된 국내 최대 의 연구자 집단(pool)이 존재하였기 때문이다. 이와 더 불어 ETRI를 세계 수준의 연구소로 만들겠다는 경영 진의 확고한 의지와 꾸준한 지원 덕분에 가능한 것이었 다. 또한 이러한 기관지의 목표가 국내 정보통신 산업 의 발전과 맞물려 국가 과학기술정책과 상호 부합하면 서 견인차로서 모범적인 역할을 담당할 수 있었던 데서 기인한다. 이처럼 ETRI Journal은 기관지로서 가지는 장점을 충분히 활용하여 짧은 시간에 우수 저널로 자리 매김할 수 있었다.

반면, 이러한 기관지로서의 특성은 ETRI Journal이 한 걸음 더 나아가 세계적인 수준의 학술지(top journal)로 성장하는 데 어느 정도 걸림돌로 작용하는 것도 사실이다. 즉, 학회 등에 뿌리를 두고 특정한 전문 분야를 대표하는 학회지에 비해 전기전자 - 정보통신 분야를 두루 섭렵하여 아우르는 현재의 ETRI Journal 성격은 일정 부분 한계로 작용하는 것이 분명하다.

그러면 어떻게 이를 극복하고 세계적인 수준의 학술 
지로 나아갈 것인가? 그 해답은 여전히 기본으로 돌아 와서, 양질의 논문이 끊임없이 투고될 수 있도록 내 외부의 인프라를 지속적으로 개선함과 동시에 세계적 수준의 독자층을 더욱 두텁게 하여 연구결과의 확산과 인용을 확대해 나가는 일일 것이다. ETRI Journal의 가치는 그림과 같이 세 바퀴가 맞물려 상승 작용하며 굴러갈 때 더욱 커질 것이다.

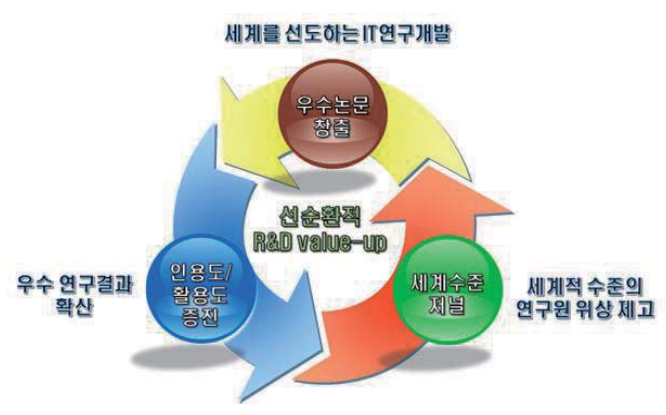

〈그림 7〉 ETRI Journal의 비전

2011년 9월 과학학술지편집인협의회가 발족하였고 이는 그동안 각기 독립적으로 우수 학술지 발행을 추구 해오던 많은 국내 학술지에게 큰 힘이 되는 소식이 아 닐 수 없었다. 그동안 ETRI Journal도 홀로 고군분투 해오면서 미국 전기전자엔지니어협회(IEEE)와 IBM 기관지 등을 벤치마킹하기도 하였지만 학술지 발간 운 영과 관련하여 공통의 애로점을 토로하고 상호 벤치마 킹하면서 정보교류를 할 수 있는 마땅한 장(場)이 없어 항상 답답한 마음이었다. 연구윤리 문제 등 특정의 이 슈가 부각되거나 최근 동향 등이 궁금해질 때면 한국과 학기술정보연구원(KISTI) 세미나, 대한의학학술지 편 집인협의회(KAMJE) 워크숍에 가서 기웃거리기도 한 것이 사실이다. 그리고 항상 느끼지만 국내의 의학 분 야 학술지를 총망라하여 체계적이고 조직적으로 운영 되고 있는 $\mathrm{KAMJE}$ 를 볼 때마다 감탄과 부러움이 앞서 곤 했다. 특히 KAMJE가 운영하는 KoreaMed
Synapse를 접했을 때, 그들은 우리보다 한 수 위에서 벌써 저만치 앞서 가고 있음을 절감하였다.

뒤늦은 감이 있지만 과편협이 발족하였으니, 이제는 셋방살이를 접고 내 집을 마련하여 새롭게 이사온 것과 같은 기분이 된다. 남은 과제는 얼마나 알차게 상호 정보 를 교류하고 또 모자라는 것은 서로 배우고 가르치며 채 워가면서 효과적으로 성장해나갈 것인가 하는 점이다. 그리하여 회원 학회지가 필요한 영양 공급을 적기에 받 아 우수 학술지로 성장하고, 나아가 양질의 학술 연구내 용을 신속히 확산할 수 있도록 지원하는 플랫폼이 되어 준다면 우리나라 과학 학술계는 물론이고 세계적인 과학 기술 발전에 그 소임을 다하는 것임을 확신한다. 0

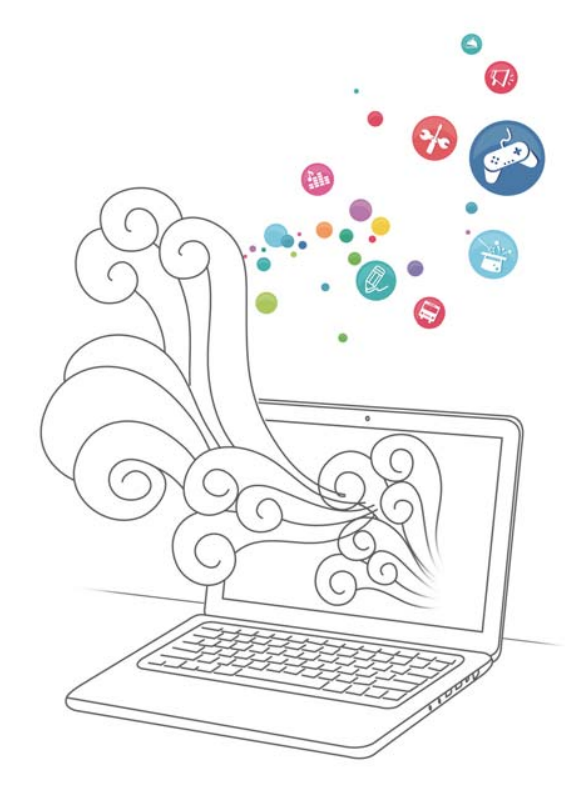

